\title{
EVALUATION OF GAMMA-GAMMA WELL LOGGING DATA APPLIED TO IRON ORE EXPLORATION - VALE GEOPHYSICAL WELL LOGGING TEST FACILITY
}

\author{
Wanderson Roberto Pereira ${ }^{1}$, Dionisio Uendro Carlos², \\ Marco Antonio da Silva Braga ${ }^{3}$ and Henry Francisco Galbiatti ${ }^{4}$
}

\begin{abstract}
The present paper shows the results of density measurement tests determined by probing of gamma-gamma geophysical well logging, performed in two stages: one at VALE Geophysical Well Logging Test Facility (GWTF), and another in boreholes for iron ore exploration. The calibration range is composed by four blocks of known density, tower-shape set, crossed by a hole with the same specifications of geological boreholes. Each block has a different composition, and a clearly determined density, as of $1.5 \mathrm{~g} / \mathrm{cm}^{3}, 2.5 \mathrm{~g} / \mathrm{cm}^{3}, 3.5 \mathrm{~g} / \mathrm{cm}^{3}$ and $4.5 \mathrm{~g} / \mathrm{cm}^{3}$. The tests recovered the expected values, since the used appliances presented a correspondence with the predicted density values as measured in actual geological boreholes.
\end{abstract}

Keywords: geophysical well logging, iron ore exploration, data evaluation.

RESUMO. 0 presente trabalho mostra os resultados dos testes de aferição de valores de densidades determinados por sonda de perfilagem geofísica gama-gama, realizados em duas etapas, uma no Campo de Teste de Perfilagem Geofísica VALE e outra em furos de sondagem para exploração de minério de ferro. 0 campo de calibração é composto por quatro blocos, de densidade conhecida, dispostos na forma de torre, atravessados por um furo nas mesmas especificações de um furo de sondagem geológica. Cada bloco tem uma composição diferente, e uma densidade bem determinada, sendo estas 1,5 g/cm ${ }^{3}, 2,5 \mathrm{~g} / \mathrm{cm}^{3}, 3,5 \mathrm{~g} / \mathrm{cm}^{3}$ e 4,5 g/cm ${ }^{3}$. $0 \mathrm{~s}$ testes recuperaram as medidas esperadas, uma vez que as ferramentas aferidas apresentaram correspondência com as densidades previstas para as litologias medidas nos furos de sondagem.

Palavras-chave: perfilagem geofísica, exploração mineral de ferrosos, aferição de dados.

\footnotetext{
1 Vale S.A., Exploração Mineral e Geologia, Centro de Tecnologia de Ferrosos - CTF, Fazenda Rio de Peixe s/n, Zona Rural, 34000-000 Nova Lima, MG, Brazil. Phone: +55(31) 3215-4301 - E-mail: wanderson.pereira@vale.com

2 Vale S.A., Exploração Mineral e Geologia, Centro de Tecnologia de Ferrosos - CTF, Fazenda Rio de Peixe s/n, Zona Rural, 34000-000 Nova Lima, MG, Brazil. Phone: +55(31)3215-4201 - E-mail: dionisio.carlos@vale.com

3 Universidade Federal do Rio de Janeiro, Departamento de Geologia - CCMN-IGEO, Sala G-058, Cidade Universitária, Av. Athos da Silveira Ramos, 274, Ilha do Fundão, 21044-020 Rio de Janeiro, RJ, Brazil. E-mail: marcobraga@geologia.ufrj.br

${ }^{4}$ Vale S.A., Exploração Mineral e Geologia, Mina de Águas Claras - MAC, Av. de Ligação, 3580, 34000-000 Nova Lima, MG, Brazil. Phone: +55(31) 3916-2195 E-mail: henry.galbiatti@vale.com
} 


\section{INTRODUCTION}

The geological drilling constitutes an important component for the research of iron ore, because it provides information on lithologies that compose the geological model used in estimation of resources and reserves (Marjoribanks, 1997).

Another function of the geological drilling refers to the analysis of boreholes, in order to determine grades, and leading for later stages of iron ore exploration and exploitation. However, drilling holes are subject to operational factors that can lead to little accurate conclusions, such as blistering, low recovering and contamination of samples, interfering in the analysis of their in situ densities.

Individual losses are associated with density measurements and lithological contact determination, whether due to the impossibility of preserving the core interstitial spaces in the drill holes, or the displacement of material during core withdrawal.

In order to minimize the possibility of mistakes regarding drill holes, it is necessary to apply additional techniques to obtain information on rocks at their natural state, before their removal by core drilling.

A way to obtain information, either on the lithological contacts, or on the in situ density, is the gamma-gamma density well logging (Ellis \& Singer, 2008).

Since gamma density logs are subject to the attenuation of gamma rays counting through a solid media, it is imperative to determine how accurate are the densities read by the gamma density logging tool related to actual densities of the media.

In order to determine such correspondence, there are some initiatives focused on the application of a gamma density tool through a media of know density such as CALLISTO and EUROPA (Samworth \& Lovell, 2001). However, most developments in geophysical well logging are intended to oil and gas exploration, thus, those facilities are designed to calibrate densities comparable to the density range found in oil and gas geological environments.

New initiatives like the TRAC Lab allow to measure densities ranging from $1.68 \mathrm{~g} / \mathrm{cm}^{3}$ to $3.08 \mathrm{~g} / \mathrm{cm}^{3}$ (Gadeken et al., 2000).

The density range found in iron ore geological environments reach apparent densities of above $4.50 \mathrm{~g} / \mathrm{cm}^{3}$ (Lima et al., 2013) that cannot be measured at those facilities, and, considering that the highest densities found in these environments are related to iron ore itself, it is necessary to develop facilities that cover the iron ore density range in order to evaluate gamma density well logging tools applied in iron ore exploration.

\section{Gamma-Gamma Well Logging}

The gamma-gamma well logging consists on the exposure of the borehole wall, to the activity of a radioactive source, and the counting of the gamma radiation which achieves to a receiver placed in a known distance from the source, towards the stone with the radiation travelling through the geological formation (Fig. 1).

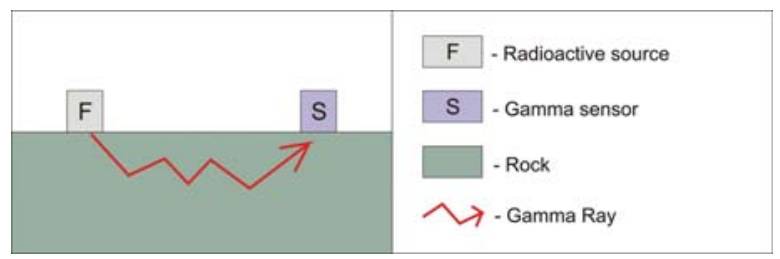

Figure 1 - Simplified schema of gamma-gamma well logging measurement.

The gamma-gamma well logging operating principle is based on the property of particles to interact with materials percolated by a gamma beam (Telford et al., 1990). The denser the percolated material is, the higher is the interaction of particles beam and the lower is the particle counting in the receiver. The relationship between the counting and the density may be described as following:

$$
N=N_{0} e^{-\mu \rho x}
$$

where $N=$ counting registered in the receiver; $N_{0}=$ counting of particles issued by the source; $\mu=$ mass absorption coefficient; $\rho=$ density, and $x=$ spacing between source and sensor (Ellis \& Singer, 2008).

The relationship between counting and density, thus, is an exponential decay, as showed on Figure 2.

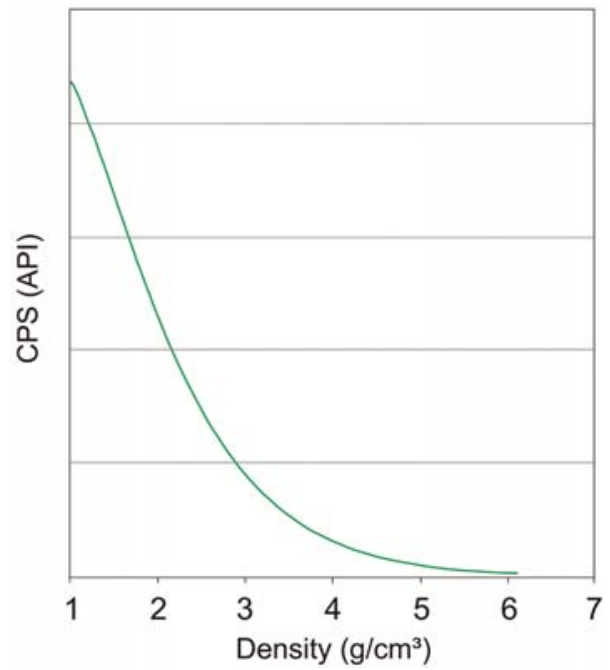

Figure 2 - Relation between gamma-radiation counting and density, for a Cesium source, in the confidence range.

There are three ways of interaction with the matter depending on the energy range associated to the particles beam: Photoelectric effect, Compton scattering, and pair production (Kaplan, 1964). Figure 3 shows the occurrence range of each kind of interaction. 


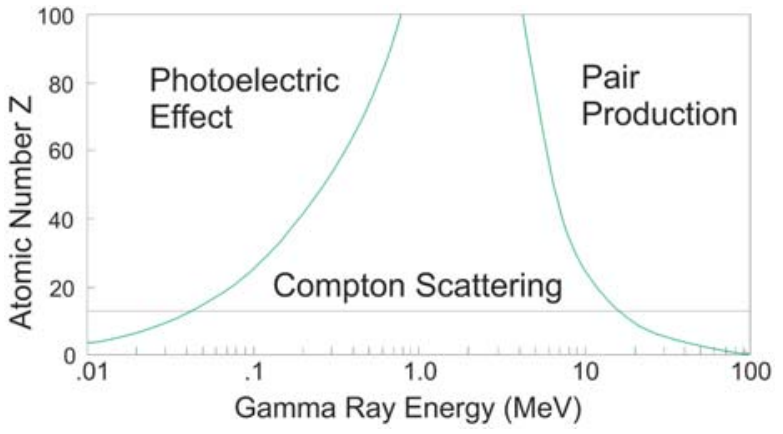

Figure 3 - Energy ranges for interaction of gamma ray with matter.

In the gamma-gamma well logging, interactions occur mainly in the energy range of the Compton scattering (Ellis, 1987).

\section{Application of Gamma-gamma Well Logging in Iron Ore Exploration}

Considering that the iron formations and hosting environment of Quadrilátero Ferrífero (MG) and Carajás (PA) mines ranges from densities lower than $1.5 \mathrm{~g} / \mathrm{cm}^{3}$ to over $4.5 \mathrm{~g} / \mathrm{cm}^{3}$ it is necessary to make density measurements into this density range.

The gamma-gamma well logging may be performed by using a source of ${ }^{137} \mathrm{Cs}$ or ${ }^{60} \mathrm{Co}$, as each one will act in a density range according to a particular relation between counting and density. Figure 4 compares the relation between counting and density, for a source of ${ }^{137} \mathrm{Cs}$ and ${ }^{60} \mathrm{Co}$.

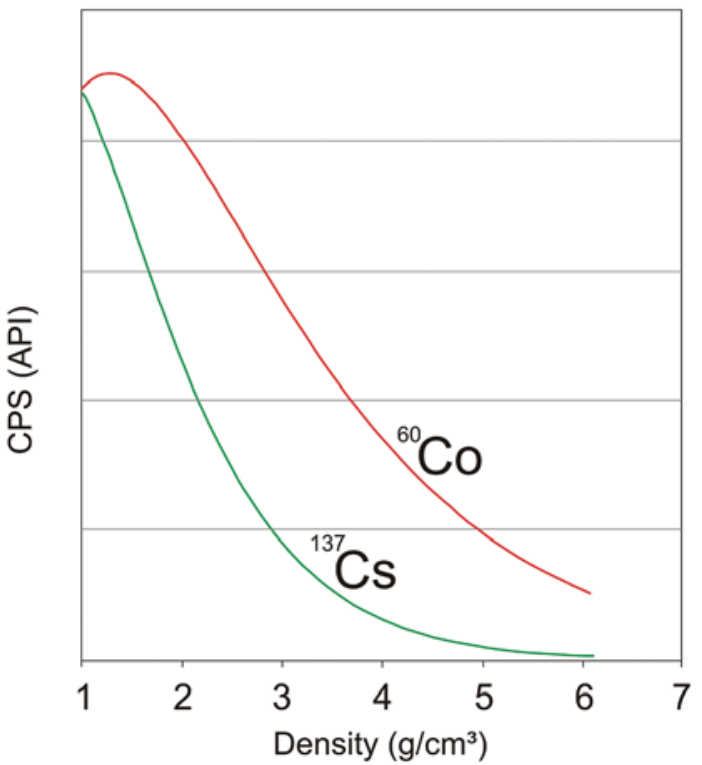

Figure 4 - Comparison between counting of gamma ray and density, for sources of Cesium (green) and Cobalt (red).

From Figure 4, we can take that, for a source of ${ }^{60} \mathrm{Co}$, higher densities can be determined with greater accuracy, since the variation of counting with density is higher than of ${ }^{137} \mathrm{Cs}$, though for lower densities, ambiguity appears on ${ }^{60} \mathrm{Co}$ counting. Considering that ${ }^{137} \mathrm{Cs}$ covers all densities expected for associated iron formations and associated lithologies, it is an ideal source for application on iron ore exploration.

Using a gamma-gamma well logging tool with a Cesium source, it is possible, thus, collect measures in both edges of the density range verified on iron ore exploration, producing wide density information for mineral exploration, as showed in Figure 5 .

Once the question related to the measured range is solved, the quality of measured data inside this range must be verified. For this purpose, reference values are used.

A possible accuracy methodology consists on taking measures by known density materials, and comparative analysis between measured and expected values, which implies especially designed facilities, as the VALE Geophysical Well Logging Test Facility (GWTF).

\section{METHODOLOGY \\ Well Logging Test Facility}

In order to make an assessment of the gamma-gamma well logging data, there are three critical parameters: (1) Depth; (2) Density; (3) Contacts.

The depth control intends to detect and correct discrepancies on depth recorded by well logging tools. Although discrepancies are more visible at depths of the order of tens of meters, the observation of this item in controlled environment allows predict potential differences between the actual contact location and the well logging tool record.

Density should be determined with precision higher than the density variation found for each studied lithology, being conditioned by the control of the composing material density in the GWTF, in this case, technological control of concrete that composes the test blocks.

The geometry of the contacts, as well as the type of transition between the blocks, should be known, and its configuration, considered in the interpretation of test data. In field boreholes, the geometry and the type of contact, that is, blunt or gradual, will determine the behavior of the density curve in transition between lithologies, as used in interpretation and contact control.

As a density data assessment tool, the construction of a composite of four concrete blocks, with different densities, vertically overlapped and crossed by a hole of same specification of field boreholes, was proposed, simulating four lithologies with different densities, as exemplified in Figure 6. 


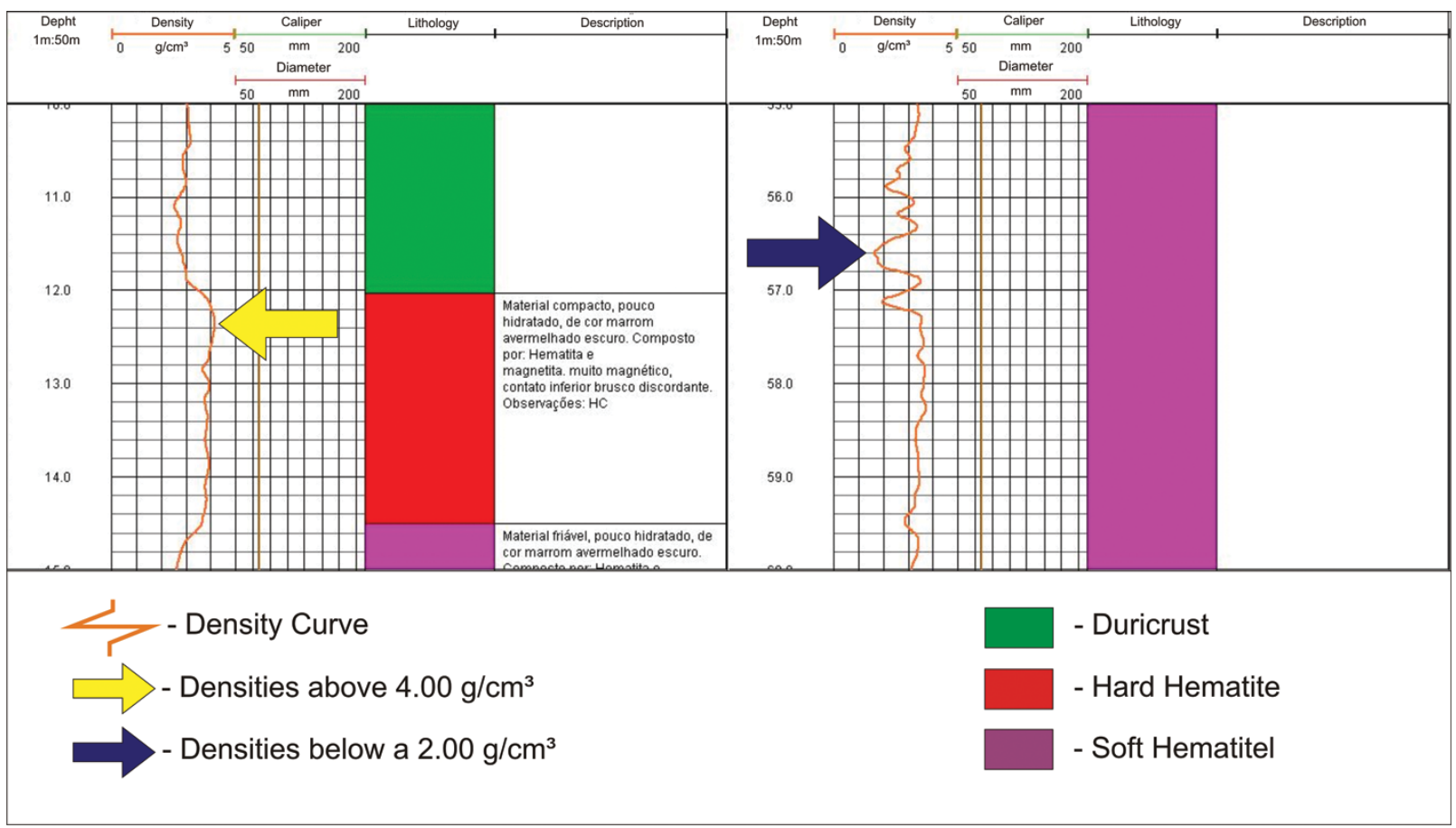

Figure 5 - Example of gamma-gamma geophysical log, showing edge measurements of density found in iron ore exploration.

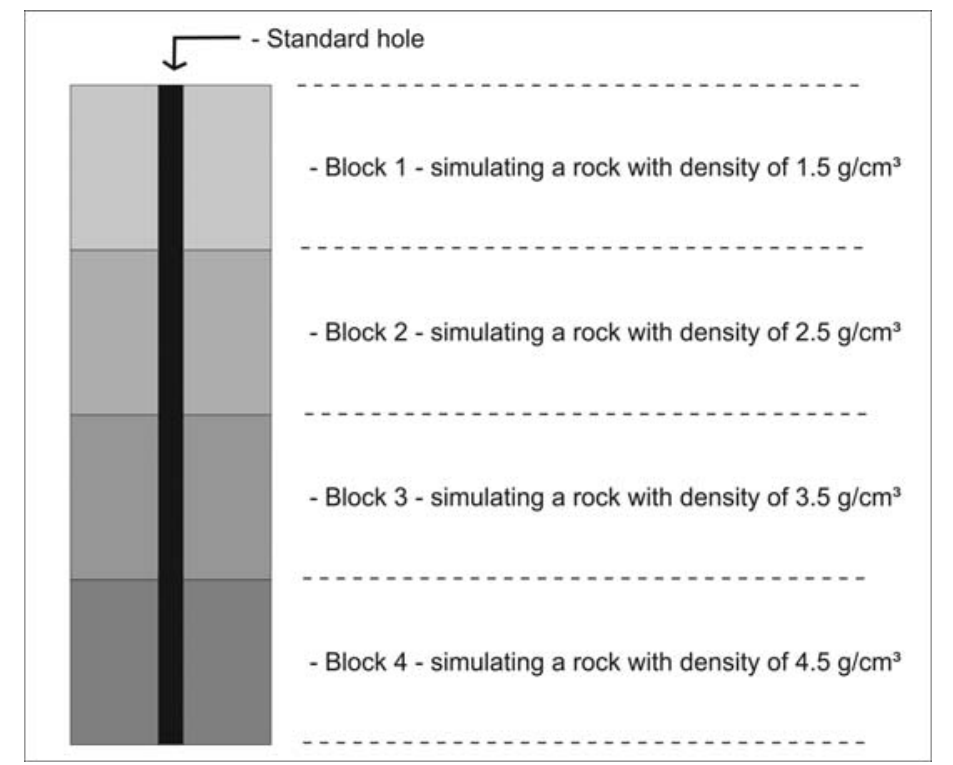

Figure 6 - Configuration of blocks on well logging towers of Geophysical Well Logging Test Facility.

Constructive methodology focus on technological control of concrete blends that composes each block, in order to ensure the density of each block regarding its value and the block homogeneity.

Each block was separately built by using a cylindrical envel- opment filled with a concrete blend of each range of density, as shown in Figure 7.

The blocks were later codified according to composing blend density, covering the density range noticed on iron ore exploration, as seen in Table 1. 

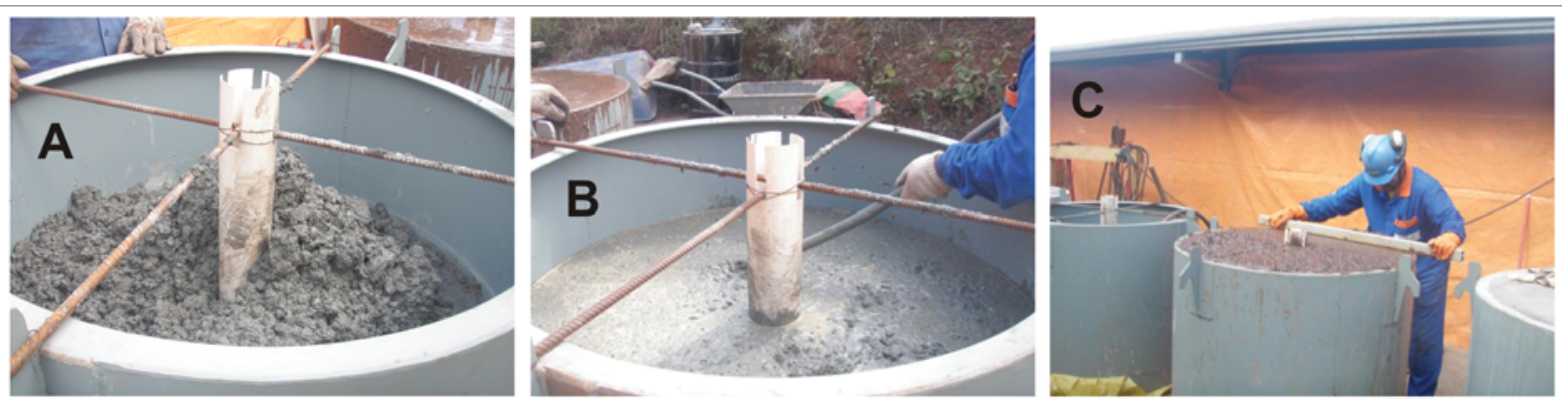

Figure 7 - Construction of well logging tower blocks. (A) Filling with controlled density blend; (B) Homogenization of filling material; (C) Finishing.

Table 1 - Composition of well logging tower blocks, with nominal densities, being the composing materials of blocks 2, 3 and 4 of different proportion.

\begin{tabular}{|c|c|c|}
\hline Block & $\begin{array}{c}\text { Density } \\
\left(\mathrm{g} / \mathrm{cm}^{3}\right)\end{array}$ & Composition \\
\hline 1 & 1.5 & Cement, grit, Styrofoam, water, additives \\
2 & 2.5 & Cement, grit, gravel, water, Styrofoam, iron ore, additives \\
3 & 3.5 & Cement, grit, gravel, water, Styrofoam, iron ore, additives \\
4 & 4.5 & Cement, grit, gravel, water, Styrofoam, iron ore, additives \\
\hline
\end{tabular}

Finally, they were set into the current configuration, with the blocks stacked in a logical sequence, as block 1 , with density of $1.5 \mathrm{~g} / \mathrm{cm}^{3}$, at the top of the sequence, and the others below it in such a way that the density increases $1.5 \mathrm{~g} / \mathrm{cm}^{3}$ for each block, from top to bottom, reaching $4.5 \mathrm{~g} / \mathrm{cm}^{3}$ at the bottom, performing a tower, as Figure 8 displays.

As using radioactive sources, GWTF has a bunker for safe storage of the source, placed so that the source travel from bunker to tower is as short as possible.

The bunker is situated beside the access to the well logging tower (Fig. 9A) and is protected by housing and a protective grid, according to Figure 9B.

Access to GWTF is facilitated to support moving equipment, such as wench carriers, typically used for tests and verifications of geophysical well logging (Fig. 10A) through a pulley system installed for this purpose in accessible position along the tower (Fig. 10B), with pulleys conveniently positioned (Fig. 10C, D and $\mathrm{E})$.

Thus, tests and measurements conducted at GWTF can be done in an expeditious manner, performing measurements through the time span of a day, with same equipment used on site at geophysical well logging campaigns.

During Vale iron ore exploration activities which involved geophysical well logging, a number of measurements were performed at GWTF, resulting in a set of data used to verify the proper operation of a tool at field works.

\section{RESULTS}

For the set of blocks composing GWTF's measurement tower, a succession of ascending density values from top to bottom are expected, according to the density of each block, from $1.5 \mathrm{~g} / \mathrm{cm}^{3}$ to $4.5 \mathrm{~g} / \mathrm{cm}^{3}$.

Whereas the tops and bottoms of each block are horizontal planes, the contacts recorded by curves are expected to be smooth, showing a transition for the nominal density of each block, as showed in Figure 11.

This is due to the influence zone of each block for which the gamma-gamma well logging device is sensitive, thus when a sensor is placed amid block 1 , in the influence zone of block 2 , it will record a density averaging $1.5 \mathrm{~g} / \mathrm{cm}^{3}$ and $2.5 \mathrm{~g} / \mathrm{cm}^{3}$ (Fig. 12A).

When the sensor is in the depth range of block 2, the same phenomenon will occur, and the density, in this case, will tend to block 2 (Fig. 12B); finally, when the sensor is positioned in the depth range of block 2, out of block 1 influence zone, it is expected to record the nominal density of the block, that is, $2.5 \mathrm{~g} / \mathrm{cm}^{3}$ (Fig. 12C).

Initially, eight grades of gamma-gamma density measurements were performed at GWTF, four of those at speeds of $1 \mathrm{~m} / \mathrm{min}$ and other four at speeds of $2 \mathrm{~m} / \mathrm{min}$, reproducing the expected behavior for density curve showed in Figure 13.

Because of the geometry of the logging tool, there is a range with suppressed values related to the space between source and sensors, and the measurement was done only when both source and sensors are totally tucked in the hole. 


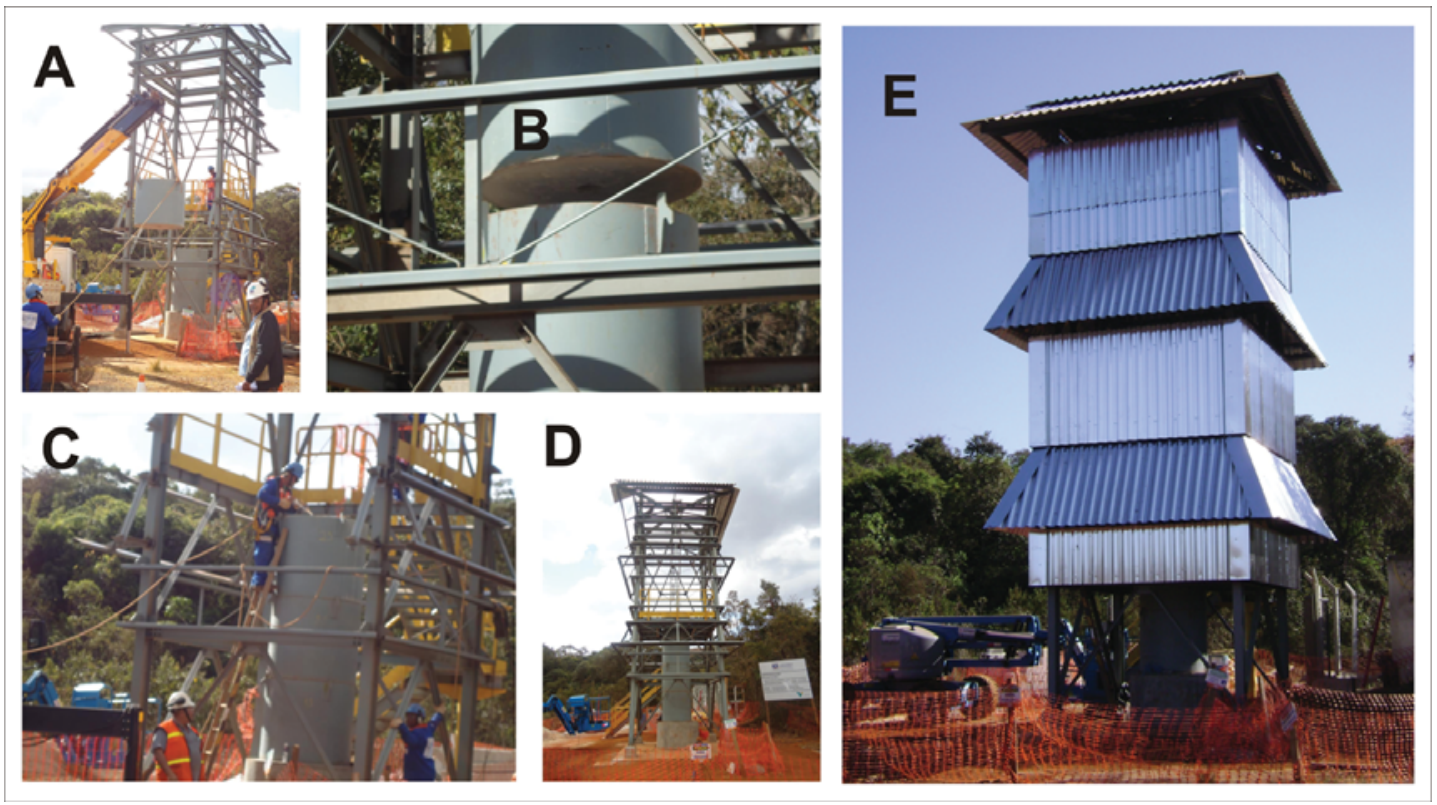

Figure 8 - Stages of well logging tower construction. (A) Lifting of blocks; (B) Placement of blocks inside the tower structure; (C) Junction and welding of blocks; (D) Final setting of blocks on tower; (E) Final setting of tower.
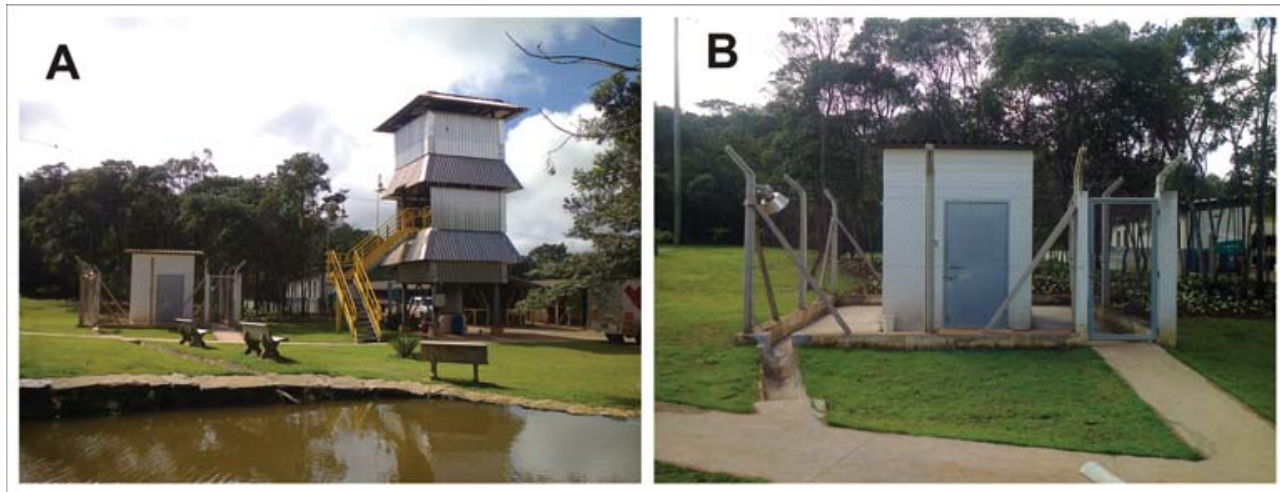

Figure 9 - Bunker for containment of radioactive source. (A) Localization of bunker in context of the Geophysical Well Logging Test Site; (B) Detail of bunker access.

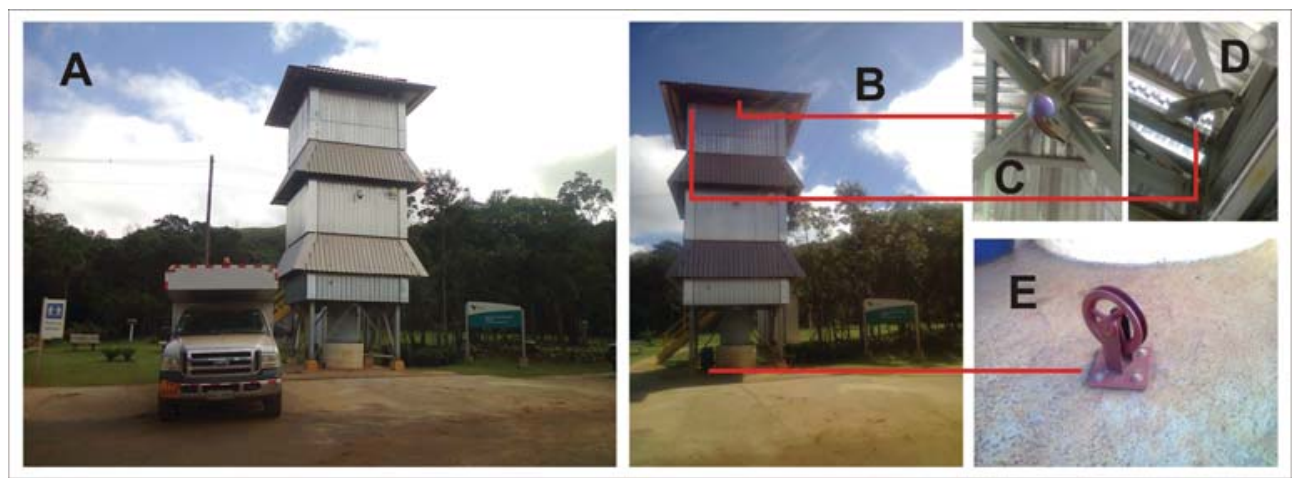

Figure 10 - Access and coupling system for vehicles and moving equipment. (A) Access to GWTF; (B) Positioning of cable pulley system; (C) Upper central pulley; (D) Upper support pulley; (E) Lower pulley. 

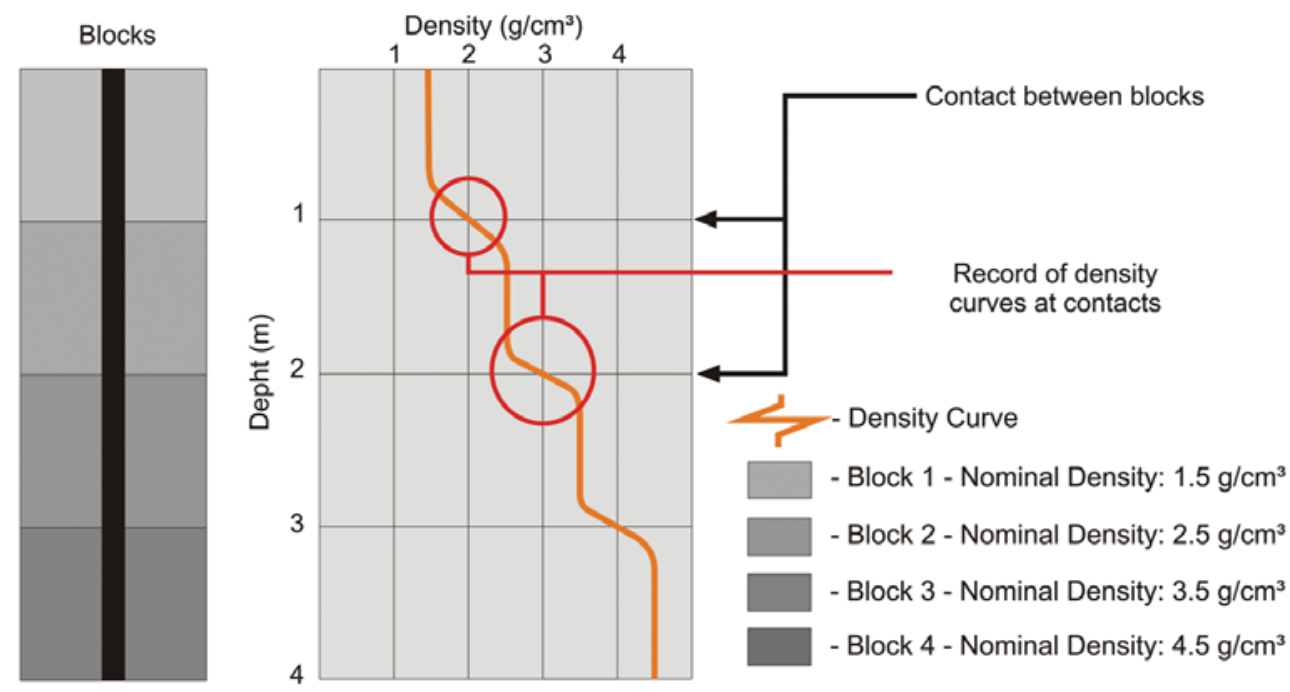

Figure 11 - Expected register for contact between blocks.
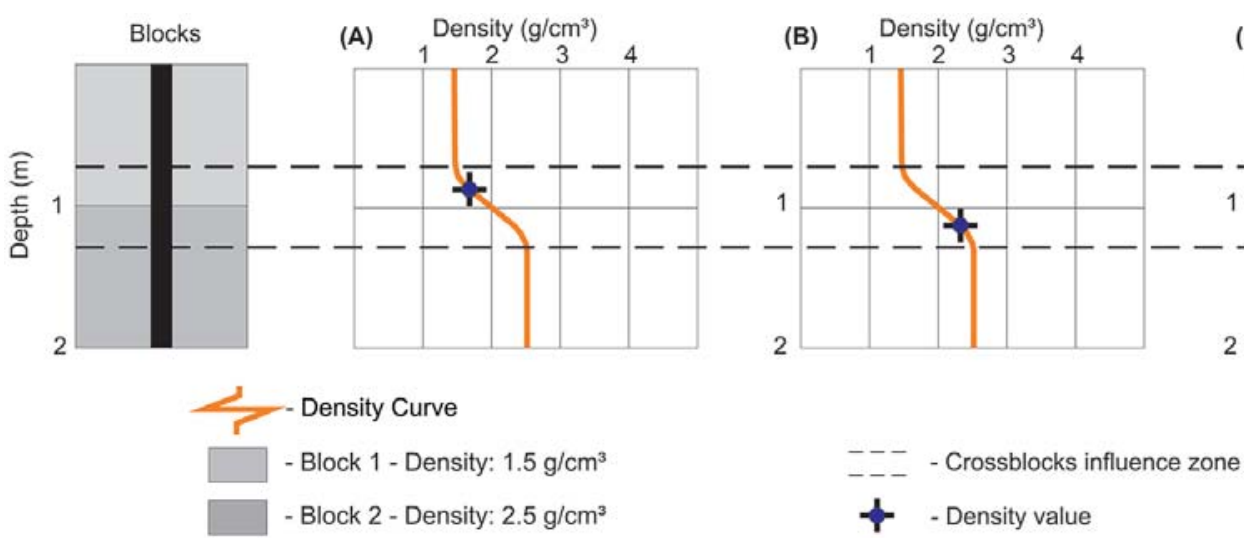

Figure 12 - Behavior of densities in the influence zone between blocks. (A) Measured density in block 1, under influence of block 2; (B) Measured density in block 2 , under influence of block 1 ; (C) Measured density in block 2 out of the influence zone of block 1.

In Figure 13, it can be noticed that there is a continuity of counting values that extends to GWTF well logging tower bottom, through which the adjacent density values can be predicted, based on the relation showed in (1), to obtain the curve present in Figure 14.

\section{CONCLUSIONS}

Regarding the expected densities range for lithologies found in iron ore exploration, obtained via gamma-gamma well logging data taken before the construction of GWTF, it consists primarily of actual geological borehole data.

The control of density variation, in this case, may be subject to geological conditioners, such as rock heterogeneity, compositional variation and conditions of borehole wall, factors that may have influence on density measurements, with discrepancies in comparison to the nominal density of each lithology, which is not a concern in the GWTF.

Being a technique traditionally applied for oil and gas exploration, data for curve calibration available for gamma-gamma well logging have a more restrict density range than that of GWTF, covering densities present in the sedimentary framework of large basins.

With the advent of the GWTF, gamma-gamma density data, which is a direct reference used in geophysical modeling in iron ore exploration, and a parameter of verification of density contrast distributions on subsurface, can be verified with a proper reference, that covers higher densities than those covered by the other existing calibration facilities. 


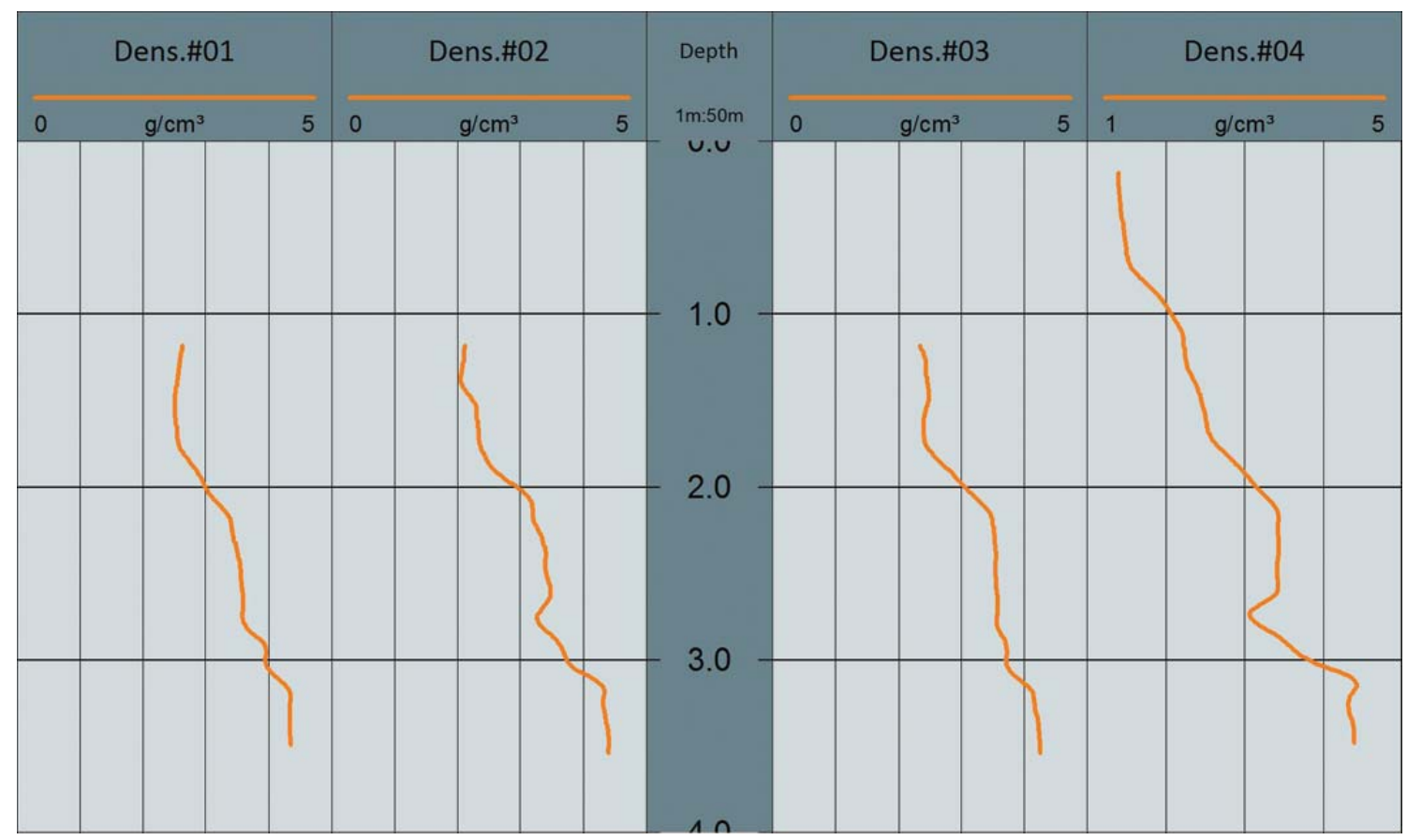

Figure 13 - Gamma-gamma density measurements performed at GWTF: Dens. \#01/\#02/\#03-2 m/min.; Dens. \#04 - 1m/min.

GWTF Gamma-gamma Log - Density x Countings

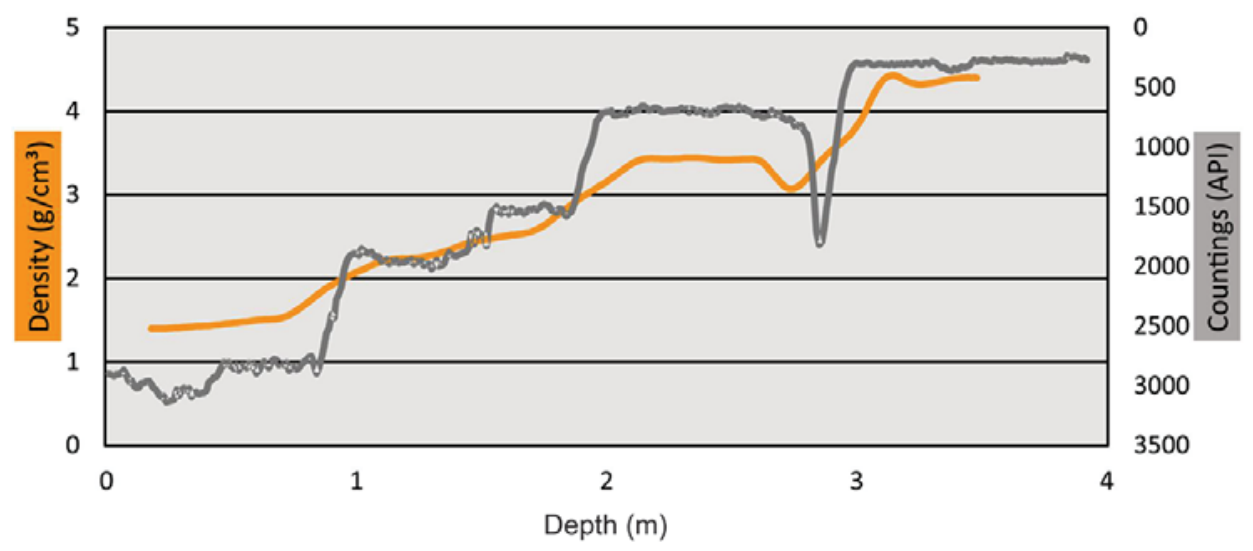

Figure 14 - Density and counting curves acquired at GWTF well logging tower values range.

The ongoing calibration of logging tools at GWTF also allows verifying if the logging tools presents any instrumental variation in density measurements by comparing the densities registered by each tool, with those expected for each block.

\section{ACKNOWLEDGEMENTS}

The authors thank to VALE Iron Ore Exploration for the support and founding of this project.

\section{REFERENCES}

GADEKEN LL, MARSCHALL D, MOAKE G, PLASEK T, SPALLONE J \& TRUAX JA. 2000. New Facilities for Characterizing and Validating Logging Instrument Performance. In: SPWLA Annual Symposium. 41., 2000. SPWLA.

ELLIS DV. 1987. Nuclear Logging Techniques. In: BRADLEY H (Ed.). Petroleum Production Handbook. SPE.

ELLIS DV \& SINGER JM. 2008. Well Logging for Earth Scientists. Elsevier, $692 \mathrm{pp}$. 
KAPLAN I. 1964. Nuclear Physics. Addison-Wesley Publishing Company. 770 pp.

LIMA PHA, SOARES JA, ROSA IBC, CARVALHORF, BRAGA MA \& SILVA MD. 2013. Petrofísica do Minério de Ferro. In: International Congress of Brazilian Geophysical Society, 13., SBGf. Rio de Janeiro, Brazil, 2013.

MARJORIBANKS R. 1997. Geological Methods in Mineral Exploration and Mining. Springer. 115 pp.

SAMWORTH JR \& LOVELL MA. 2001. CALLISTO - A New World Standard Facility for the Calibration of Nuclear Well Logs. CSPG. In: The CSPG Annual Convention 2001.

TELFORD WM, GELDART LP \& SHERIFF RE. 1990. Applied Geophysics. Cambridge University Press. 792 pp.

Recebido em 3 novembro, 2014 / Aceito em 28 outubro, 2016

Received on November 3, 2014 / Accepted on October 28, 2016 